\title{
Studies of the Influence of Temperature and the Energy State of the Surface Layer of Adsorbents on Wall Effects in Soap-Based Greases
}

\author{
Maciej Paszkowski $^{1} \cdot$ Roman Wróblewski $^{2} \cdot$ Aleksandra Walaszczyk $^{1}$
}

Received: 1 November 2016/ Accepted: 18 December 2016/Published online: 24 December 2016

(C) The Author(s) 2016. This article is published with open access at Springerlink.com

\begin{abstract}
This paper presents the results of studies of wall effects in commercial soap-based greases LT4-S2 and HUTPLEX EP-2, thickened with, respectively, lithium 12-hydroxystearate and overbased calcium sulfonate. The studies were conducted in the presence of five different materials: copper alloy C11000, bronze B476, EPDM rubber and PTFE and PU thermoplastics. The influence of the energy state of the surface layer of the adsorbents and temperature (ranging from -20 to $60{ }^{\circ} \mathrm{C}$ ) on the intensity of wall effects was investigated. Changes in the structural viscosity and shear stress in the boundary layer area in the greases and the soap-based thickener's ability to adsorb on the surfaces of the adsorbents were determined by evaluating the rheological parameter plateau modulus.
\end{abstract}

Keywords Grease · Wall effect · Wall slip · Boundary layer - Superficial layer - Surface free energy - Diffusion . Plateau modulus

\section{Introduction}

Grease is a polydisperse system in which one phase is dispersed in another (a dispersion medium). The system is chemically and physically heterogenous and has complex

Maciej Paszkowski

maciej.paszkowski@pwr.edu.pl

1 Department of Fundamentals of Machine Design and Tribology, Wroclaw University of Science and Technology, Ignacego Lukasiewicza 7/9, 50-371 Wrocław, Poland

2 Department of Founding, Automation and Plastics, Wroclaw University of Science and Technology, Smoluchowskiego 25, 50-372 Wrocław, Poland rheological properties. The properties depend on the microstructure of the grease, the external factors, the flow intensity as well as on the parameters of the structural elements with which the grease is in close contact (e.g., the geometric structure of the surface). The research results reported by many researchers show that greases form a boundary layer which is from ten nanometers to ten micrometers thick. An extensive survey of the literature on the subject can be found in, for example, [1-6]. The boundary layer is the result of the grouping of the grease's ensembles of thickener particles on the surface of the material being lubricated. The intensity of this phenomenon is highest in the case of soap-based greases [7, 8]. The process is catalyzed by anisotropically shaped (lengthwise and crosswise) particles with active sites on their ends. Physicochemical interactions are mainly responsible for the grouping of the particles on the surface. As a result of the diffusion of thickener particles onto the material surface, an area depleted of thickener, with distinctly lower structural viscosity, forms close to this surface. The rheological properties of the area are similar to those of the Newtonian fluid [9]. Some of the ensembles of particles are "pulled out" of the bulk of the grease. The structure of the thickener in this area is less dense and less cross-linked (Fig. 1).

The formation of a boundary layer in greases is of great significance for engineering practice. There are several works proving that the boundary layer affects the pumpability of greases in axially symmetric conduits and clearances $[11,12]$. It has been proved that the flow resistances of greases in lubrication pipes made of metals are smaller than that in polymeric pipes [12]. The explanation of this phenomenon can contribute to the optimization of lubrication systems with regard to their reliability and the minimization of energy consumption by the grease 
(a)

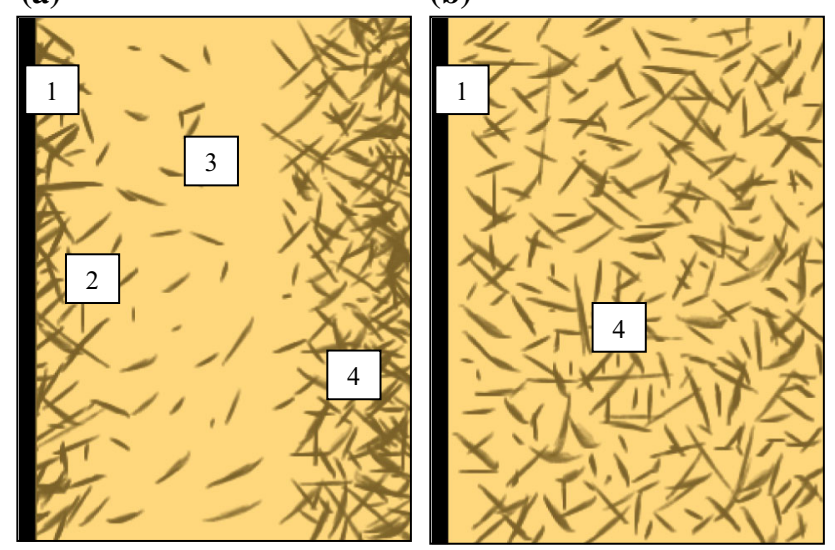

Fig. 1 Formation of superficial layer and boundary layer in grease flowing in vicinity of wall made of material which: $\mathbf{a}$ is able to adsorb thickener particles, $\mathbf{b}$ is not able to adsorb thickener particles, 1 material wall, 2 superficial layer (grease thickener particles adsorbed on surface of material wall), 3 boundary layer (region with reduced thickener concentration and lower structural viscosity), 4 bulk of grease [10]

pumping unit. There are also works proving that wall effects can occur in greases filling the clearances of clearance seals used as, among other things, structural members of mining belt conveyor rollers. In this case, one of the functions of the greases is to protect the roller bearing chamber against contamination and moisture penetration from the outer environment. The problem affecting rollers in the course of their long service is the breakdown of the grease and its escape from the seal clearance due to centrifugal forces and wall effects. In [13, 14], it was found that the possible cause of the problem is energetic bonds forming between the thickener and the seal surface, facilitating the outflow of the base oil. Consequently, the life of the rollers is shortened as a result of, among other things, their easier contamination in the dust-laden environment. Using microparticle image velocimetry ( $\mu \mathrm{PIV}$ ), wall effects were observed also during the shearing of grease in the clearances of axial and radial labyrinth seals $[15,16]$. There are also research works indicating that wall effects in greases affect the effectiveness of the lubrication of slide bearings. For example, in [17] it was shown that the adsorption of thickener particles on the walls of slide bearing inlet channels, resulting in the formation of a permanent superficial layer there, can hinder the flow of grease into the bearing interspace. Similar conclusions concerning the influence of wall effects on the lubrication of slide bearings can be found in [18], where the resistances of flow of greases in a swinging bearing were investigated. The obliteration of the lubrication channel and the intensive adsorption of thickener on the surfaces of the journal and the bush, situated in the immediate vicinity of the channel, were clearly visible, especially for higher grease flow rates and longer bearing service. This made the precision supply of the lubricant to the bearing interspace impossible. Ultimately, wall effects affect the quality of lubrication of tribological pairs and the formation of a lubricating film separating the friction surfaces. The rate at which the lubricating film forms depends on, among other things, the viscosity of the oil base and the structure of the thickener [19]. In [20], it was shown that from among the many rheological parameters, such as the yield value, the apparent viscosity, the critical strain and the moduli of viscoelasticity, storage modulus $G^{\prime}$ was the principal indicator of the tribological properties of greases. The low storage modulus would increase the grease's ability to form a superficial layer in the friction pair. The findings of the rheological investigations were confirmed using another measuring method-optical interferometry. The increase in the thickness of the superficial layer forming on the races of rolling bearings in the elastohydrodynamic (EHD) lubrication regime can intensify oil bleeding from the thickener network and the escape of the oil to the outside of the friction pair [21]. Also the slip of grease close to the structural elements of rolling bearings, i.e., rolling elements, rings, cages and seals, seems to be an interesting problem. The lubrication of rolling bearings is a very chaotic process and depends on the initial conditions. Wall effects may contribute to the formation of grease reservoirs, mentioned in [22]. Considering that they push greases out of the bearing interspace, grease reservoirs created during the churning phase determine the lubrication quality and the grease life in the later stages of bearing service. Many researchers have noted the influence of wall effects also on the lubrication of friction pairs with lubricating oils in the elastohydrodynamic (EHD) lubrication regime [23, 24]. In such cases, the wall effects' mechanism is limited to the repulsion or attraction of lubricating oil particles from/to the surface being lubricated. It has been proved that wall effects can lead to a reduction in friction [25]. Surface free energy has an influence on the interaction between oil and the surface being lubricated. When the surface free energy is low, it initiates lubricating oil slip near the walls of the structural elements of friction pairs $[25,26]$.

Considering that the occurrence of wall effects in greases is an important problem from the point of view of the tribology, building and operation of machines, the authors of the present paper decided to investigate this problem. The influence of temperature and the energy state of the surface layer of selected metallic and polymer materials (further referred to as adsorbents) on the rheological properties of the boundary layer in commercial soap-based greases were assessed. The selected materials can be used for making grease pipes or other machine 
lubrication system components, as well as slide systems, including seals.

\section{Materials}

In total, five adsorbent samples, made of, respectively, EPDM (ethylene propylene diene monomer) rubber with a hardness of $70{ }^{\circ} \mathrm{Sh} \mathrm{A}$, copper alloy C11000, bronze B476, PTFE (polytetrafluoroethylene) and PU (polyurethane), were subjected to tests. The metallic alloy samples and the thermoplastic samples had been made by lathing and then finishing in order to obtain very similar roughness of their surfaces as well as to remove the spiral grooves left after lathing. The rubber sample had been cut out of a sheet by means of a blanking die. The surface of this sample had not been subjected to mechanical working. Table 1 shows the results of examining the geometric structure of the surface of the samples by means of a contact profilometer. The arithmetic mean deviation of the roughness profile did not exceed $1.77 \mu \mathrm{m}$. Surface roughness was measured over an interval of $4 \mathrm{~mm}$ using a handheld profilometer.

Wall effects occurring in the vicinity of the above adsorbents were studied for two soap-based greases with complex thickeners, popular in Poland, i.e., lithium grease GREASEN LT4-S2 and calcium grease HUTPLEX EP-2 (Orlen Oil, Cracow, Poland). The characteristics of the tested greases are presented in Table 2. The particular greases were selected since they were characterized by similar worked penetration values. The two greases are commonly used in the mining industry (in both surface and underground mines).

Grease LT4-S2 is used mainly to lubricate rolling bearings, machine flexible connectors and guides and equipment components. The grease contains anti-corrosion, anti-oxidation and lubricating ability-enhancing additives. According to the manufacturer's data, grease HUTPLEX EP-2 is characterized by excellent adhesion to the surfaces being lubricated. It is used mainly to lubricate machines in the mining, metallurgical, heavy and maritime industries. It is particularly suitable for lubricating heavily loaded pairs

Table 1 Results of examining geometric structure of adsorbents surface

\begin{tabular}{llrrr}
\hline Material & \multicolumn{4}{l}{ Roughness $(\mu \mathrm{m})$} \\
\cline { 2 - 5 } & $\mathrm{Ra}$ & $\mathrm{Rz}$ & $\mathrm{Rm}$ & $\mathrm{Rt}$ \\
\hline EPDM & 1.77 & 9.1 & 12.6 & 12.6 \\
B476 & 1.41 & 10.0 & 12.7 & 14.4 \\
C11000 & 1.36 & 9.9 & 13.9 & 15.6 \\
PTFE & 1.38 & 8.8 & 11.1 & 11.4 \\
PU & 0.93 & 5.6 & 6.7 & 6.7 \\
\hline
\end{tabular}

operating in high dustiness and water and brine exposure conditions.

\section{Methods}

\subsection{Rheological Tests}

The boundary layer of the greases was investigated using a Physica Anton-Paar MCR 101 rotational rheometer with a torque range of $0.1 \mu \mathrm{Nm}-150 \mathrm{mNm}$. The rheometer operated in the plate/plate configuration with a constant measuring gap height of $1 \mathrm{~mm}$. The measuring gap setting accuracy was $\pm 0.001 \mathrm{~mm}$. The rheometer comprised a P-PTD200 Peltier heating/cooling unit and an H-PTD200 insulating flange with air circulation inside the measuring head. A steel measuring spindle in the form of a $\phi 50-\mathrm{mm}$ plate, onto which samples of the adsorbents would be stuck, was used for the tests. A schematic of the rheometer measuring head is shown in Fig. 2.

Each time after an adsorbent was stuck on the spindle, the zero gap and the measuring gap would be set and the moment of inertia of the modified spindle would be determined. Then, changes in torque $M$ of the modified spindle would be measured as a function of its inclination angle $\phi$, at a constant rotational speed of $0.3 \mathrm{rpm}$. The tests would be conducted in air for $1 \mathrm{~min}$, without grease. If the moment of inertia of the spindle was within the allowable interval of -0.05 to $0.05 \mu \mathrm{Nm}$, the next testing stage would begin. Figure 3 shows an exemplary result of the calibration of the rheometer with the modified measuring spindle (with a polyurethane sample stuck on) installed.

During the tests, the grease samples would be thermostated at a constant temperature with an accuracy of $\pm 0.01{ }^{\circ} \mathrm{C}$. Prior to each measurement, they would be kept at a constant temperature in the rheometer head for $5 \mathrm{~min}$ after the set temperature stabilized. Measurements would be repeated five times.

The tests were conducted in two stages: (1) at an increasing shear rate and (2) in dynamic oscillatory conditions. In the first stage, the greases would be sheared within a shear rate $(\dot{\gamma})$ range of $10^{-4}-10^{0} \mathrm{~s}^{-1}$ and a temperature $(T)$ range of -20 to $60{ }^{\circ} \mathrm{C}$. According to the literature on the subject [27], the adopted shear rate range guaranteed that the rheological properties of the greases in the boundary layer area would be measured. The dependences between shear stress $\tau$ and structural viscosity $\eta$ of the greases as a function of the rate of their shear were determined. Dynamic oscillatory tests were carried out at the temperature at which differences in the structural viscosity of the boundary layer of the greases flowing close to the tested adsorbents were largest. During the tests, the greases would be sheared within their linear viscoelasticity 
Table 2 Composition and properties of tested greases, acc. to manufacturer's data

\begin{tabular}{lll}
\hline & GREASEN LT4-S2 & HUTPLEX EP-2 \\
\hline Thickener & Lithium 12-hydroxystearate & Overbased calcium sulfonate \\
Oil base & Mineral oil \\
Oil base viscosity at temp. $40{ }^{\circ} \mathrm{C}(\mathrm{cSt})$ & 85 & 420 \\
Application temperature $\left({ }^{\circ} \mathrm{C}\right)$ & $\mathrm{Od}-30$ do 120 & $\mathrm{Od}-30$ do 180 \\
Dropping point $\left({ }^{\circ} \mathrm{C}\right)$ & 185 & 300 \\
Worked penetration at $25^{\circ} \mathrm{C}(\mathrm{mm} / 10)$ & 285 & 302 \\
Consistency class, acc. to NLGI & 2 & $1 / 2$ \\
\hline
\end{tabular}

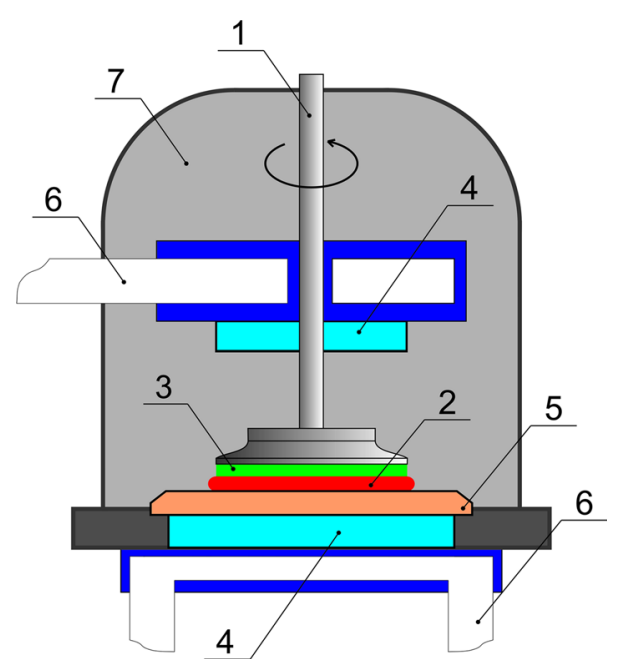

Fig. 2 Schematic of rheometer measuring head. 1 Measuring spindle, 2 lubricating grease, 3 tested adsorbent, 4 Peltier element, 5 measuring plate, 6 counter cooling, 7 insulating flange

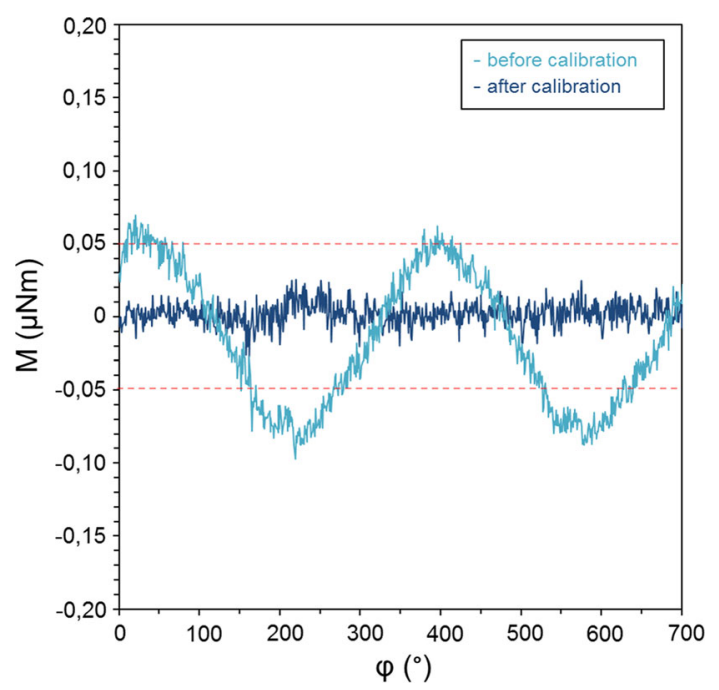

Fig. 3 Result of calibrating rheometer with modified measuring spindle (with polyurethane plate stuck on) installed

range (LVR). The dependences between storage modulus $G^{\prime}$, loss modulus $G^{\prime \prime}$ and damping coefficient $\tan \delta$ as a function of oscillation frequency $\omega$, within a range of $10^{-1}-10^{2} \mathrm{rad} / \mathrm{s}$ and at a constant strain $\gamma$ of $0.1 \%$, were determined. In the next stage, plateau modulus $G_{N}^{0}$ would be determined. This parameter, described in detail in Ferry's work [28], was used to evaluate the degree of crosslinking of the microstructure of the thickener within the boundary layer area. The parameter was developed on the basis of one of the theories concerning the dynamics of entangled polymers - the de Gennes tube model (also called the de Gennes reptation model) [29]. The modulus would be determined using the MIN method proposed by $\mathrm{Wu}[30,31]$ :

$G_{N \exp }^{0}=G^{\prime}(\omega)_{\tan \delta \rightarrow \min }$

\subsection{Contact Angle and Free Surface Energy Tests}

The surface free energy of the surface layer of the adsorbents was determined by measuring the static angle of wetting them with probe liquids. For this purpose, a DSAHT12 goniometer equipped with a thermostatic chamber with a temperature controller, a video camera and a computer system for visualizing measurements and recording drop dimensions was used. Prior to the investigations, the metallic and plastic samples had been cleaned with, respectively, extraction naphtha and distilled water. The experiments were carried out in air at a constant (with the acceptable accuracy of $\pm 2{ }^{\circ} \mathrm{C}$ [32]) temperature. Before each wetting (contact) angle measurement, the samples would be kept at a constant temperature in the thermostatic chamber for $5 \mathrm{~min}$ after the set temperature stabilized. Similarly as the dynamic oscillatory rheological tests, measurements of the contact angle with the probe liquids were taken at the temperature at which the influence of the adsorbent wall material on the structural viscosity of the greases in the boundary layer area was most evident and the wall effects were most intensive. Five apolar and bipolar standard liquids: pure water, diiodomethane, formamide, ethylene glycol and glycerol, with known values of surface free energy $\gamma_{L}$, polar component $\gamma_{L, p}$ and dispersion component $\gamma_{\mathrm{L}, \mathrm{d}}$, were used as the probe substances. The properties of the probe liquids are presented in Table 3. The polar component is the sum of the components which define the polar, hydrogen, induction and 
Table 3 Basic properties of probe liquids, with indicated source literature

\begin{tabular}{lllcl}
\hline Probe liquid & $\mathrm{SFE} \gamma_{\mathrm{L}}\left(\mathrm{mJ} / \mathrm{m}^{2}\right)$ & Dispersion component $\gamma_{\mathrm{L}, \mathrm{d}}\left(\mathrm{mJ} / \mathrm{m}^{2}\right)$ & Polar component $\gamma_{\mathrm{L}, \mathrm{p}}\left(\mathrm{mJ} / \mathrm{m}^{2}\right)$ & References \\
\hline Pure water & 72.1 & 19.9 & 52.2 & {$[33]$} \\
Diiodomethane & 50.0 & 47.4 & 2.6 & {$[34]$} \\
Formamide & 56.9 & 23.5 & 33.4 & {$[34]$} \\
Ethylene glycol & 72.8 & 21.8 & 51.0 & {$[35]$} \\
Glycerol & 72.1 & 19.9 & 52.2 & {$[33]$} \\
\hline
\end{tabular}

acid-base intermolecular interactions, except for dispersion interactions. The latter are expressed by the dispersion component.

Drops of the probe liquids would be placed on the samples using the sessile drop technique. The contact angles would be determined through a geometrical analysis of the image of the drop after $5 \mathrm{~s}$ since its deposition on the surface, after the thermodynamic equilibrium was reached. This procedure would be repeated five times. It should be noted that the surface layers of all the tested adsorbents had been so prepared as to reduce to minimum plastic-air diphase areas under the surface of the sessile drop and to avoid a situation in which the drop could find itself in different metastable states.

The surface free energy $\left(\gamma_{\mathrm{S}}\right)$ of the tested materials was calculated on the basis of the contact angles $(\Theta)$ measured by the probe liquids, using two dispersion and polar component methods, i.e., the Owens-Wendt method [36] and the $\mathrm{Wu}$ method [37]. In the former method, the surface tension in the solid/probe liquid contact area has the following form:

$\gamma_{S L}=\gamma_{S}+\gamma_{L}-2 \cdot\left(\gamma_{S, d} \cdot \gamma_{L, d}\right)^{0.5}+2 \cdot\left(\gamma_{S, p} \cdot \gamma_{L, p}\right)^{0.5}$,

where the subscripts $p$ and $d$ stand for, respectively, the polar and dispersion component of the surface free energy of the solid or the probe liquid. Wu proposed a different form of Eq. (2). The difference consists in replacing the last two terms (the geometric means) in Eq. (2) with harmonic means:

$\gamma_{S L}=\gamma_{S} \cdot \gamma_{L}-\frac{4 \cdot \gamma_{S, d} \cdot \gamma_{L, d}}{\gamma_{S, d}+\gamma_{L, d}}-\frac{4 \cdot \gamma_{S, p} \cdot \gamma_{L, p}}{\gamma_{S, p}+\gamma_{L, p}}$

By simplifying Young equation [38], initially derived from the condition of the equilibrium of the forces representing the surface tension in the point of contact between the three phases: the solid, the liquid and the pair, to the form:

$\gamma_{S}=\gamma_{S L}+\gamma_{L} \cdot \cos \Theta$

and substituting it into Eqs. (2) and (3), one gets relations for determining the surface free energy of the tested adsorbents by means of the probe liquid shown in Table 3 .

\section{Results and Discussion}

\subsection{Rheological Properties of Boundary Layer in Greases}

The results of the rheological tests carried out at an increasing shear rate indicate that wall effects occurred in the greases at low shear rates $(\dot{\gamma})$, i.e., ranging from $10^{-5}$ $10^{-0} \mathrm{~s}^{-1}$. In the above shearing conditions, the structural viscosity $(\eta)$ curves had the shape of an inverted parabola. The parabolas clearly differed from one another in the location of their extrema. The maximum structural viscosity value recorded in the whole boundary layer area was determined by the grease used, the kind of adsorbent and the temperature (Fig. 4).

It should be noted that the largest differences between the tested greases were revealed at sub-zero temperatures. In the case of grease LT4-S2, at a temperature of $-20{ }^{\circ} \mathrm{C}$ no clear influence of the wall material on the formation of a boundary layer was visible and the differences in the recorded structural viscosity values were within the margin of error. In the temperature range of $0-60{ }^{\circ} \mathrm{C}$, the two soapbased greases flowing close the adsorbents would behave similarly. The strongest effect of the wall material on the structural changes in the boundary layer area of the tested greases was observed at the temperature of $60{ }^{\circ} \mathrm{C}$. Figure 5 shows exemplary structural viscosity and shear stress curves for grease LT4-S2, recorded in the vicinity of the tested adsorbents at the temperature of $60{ }^{\circ} \mathrm{C}$. Because of the close similarity, no curves for grease HUTPLEX EP-2 were included in the figure.

In the second stage of the rheological studies, dynamic oscillatory tests were carried out on the greases flowing close to the adsorbents. The tests would be conducted in the linear viscoelasticity range (LVR) of the greases, at the temperature of $60^{\circ} \mathrm{C}$. The aim of the experiments was to assess the ability of the greases to form a superficial layer on the walls of the tested adsorbents by analyzing the degree of cross-linking of the thickener in the boundary layer area. For this purpose, modulus $G_{\text {Nexp }}^{0}$, described in more detail in Sect. 3.1, was determined. The lower the value of the plateau modulus, the more the thickener 


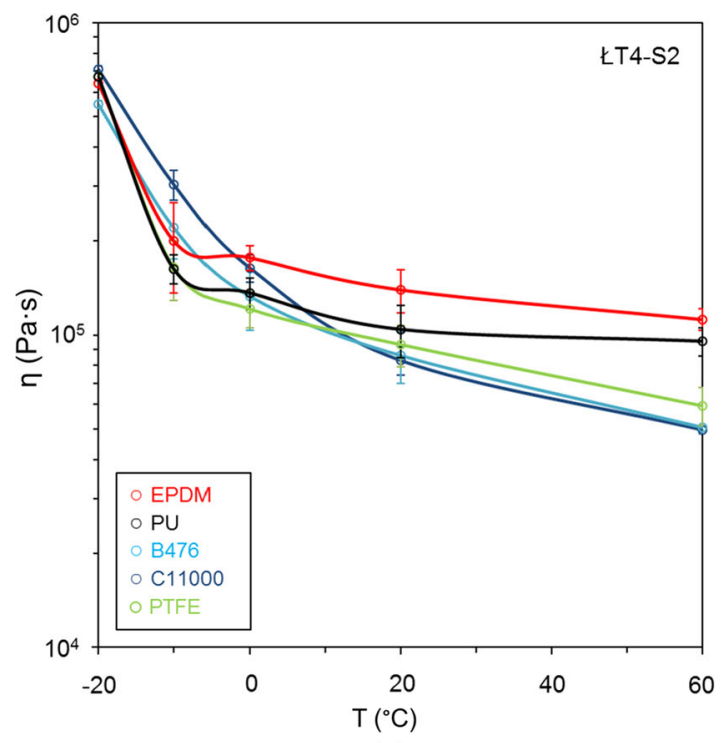

(a)

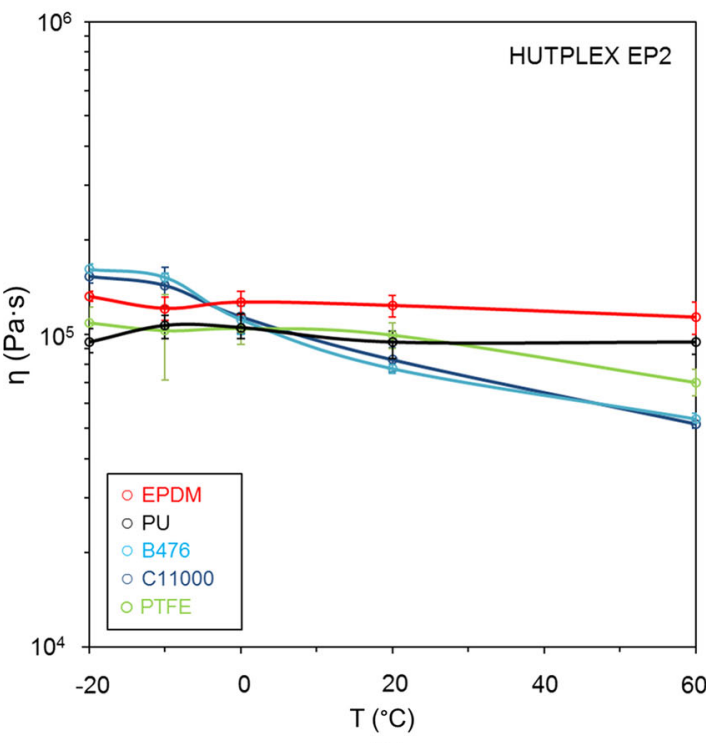

(b)

Fig. 4 Highest structural viscosity $\eta$ values for: a lithium grease and $\mathbf{b}$ calcium grease, recorded in vicinity of tested adsorbents at temperature of -20 to $60{ }^{\circ} \mathrm{C}$

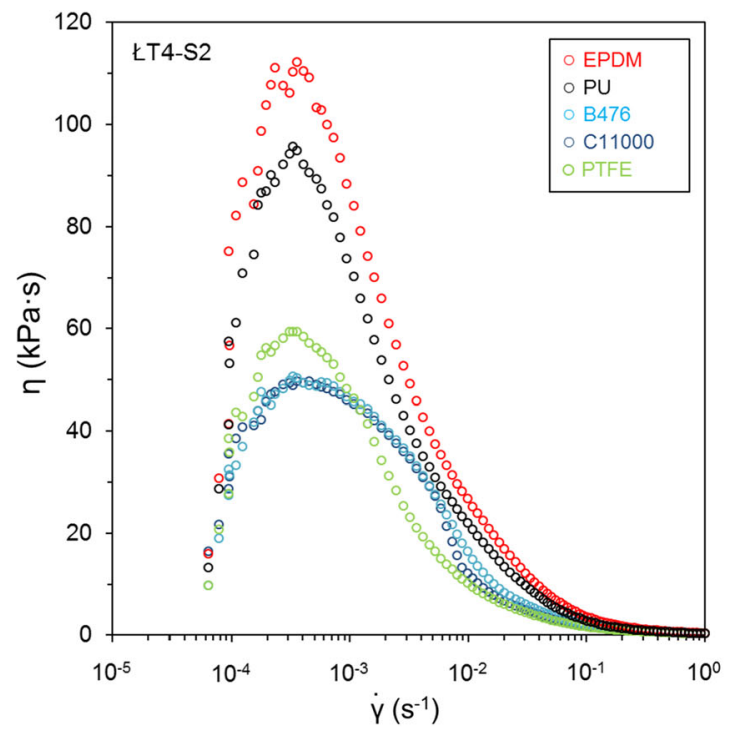

(a)

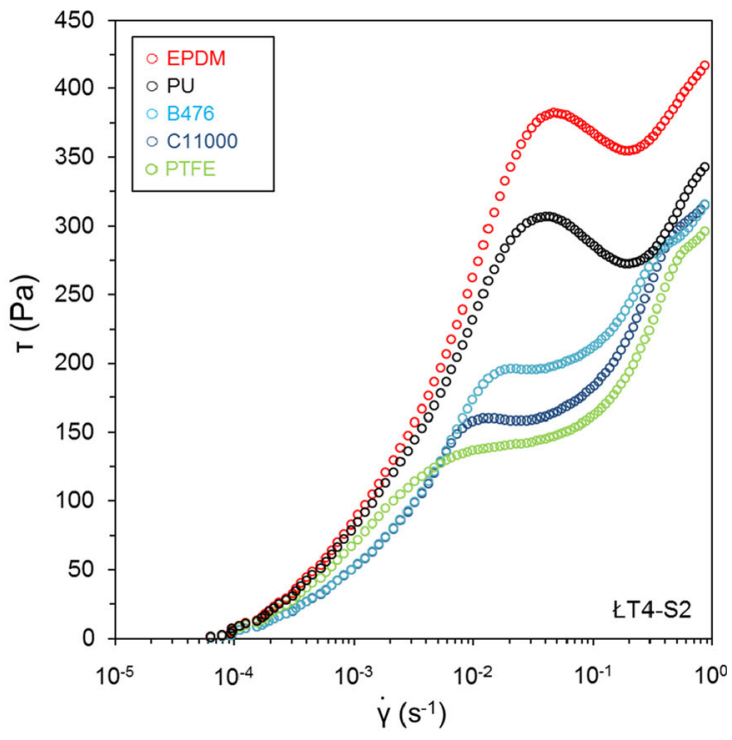

(b)

Fig. 5 a Structural viscosity $\eta$ and $\mathbf{b}$ shear stress $\tau$ in lithium grease, recorded in vicinity of tested adsorbents at temperature of $60{ }^{\circ} \mathrm{C}$

ensembles in the grease migrate to the adsorbent surface, forming a lubricating film, and the greater the slip of the grease flowing close to the material wall. Figures 6, 7 and 8 show storage modulus $G^{\prime}$, loss modulus $G^{\prime \prime}$ and damping coefficient $\tan \delta$ as a function of oscillation frequency $\omega$ for grease LT4-S2 and grease HUTPLEX EP-2. Inflexion points and the corresponding oscillation frequencies were determined from the curves shown in Fig. 8. An iterative algorithm based on the Gauss-Newton method was used for this purpose. Then, for the same oscillation frequencies, the values of the storage modulus were read off the curves shown in Fig. 6, in accordance with relation (1). The curves are supplemented with the loss modulus-oscillation frequency curves shown in Fig. 7.

According to the results of the dynamic oscillatory tests, the highest plateau modulus value was recorded close to EPDM. The mean values of this parameter for the lithium grease and the calcium grease amounted to, respectively, 34,294 and 24,816 Pa (Table 4). This means that from all the tested adsorbents, the EPDM rubber reacted to the least degree with the soap-based thickener. The lowest plateau modulus values were recorded for the greases flowing close 


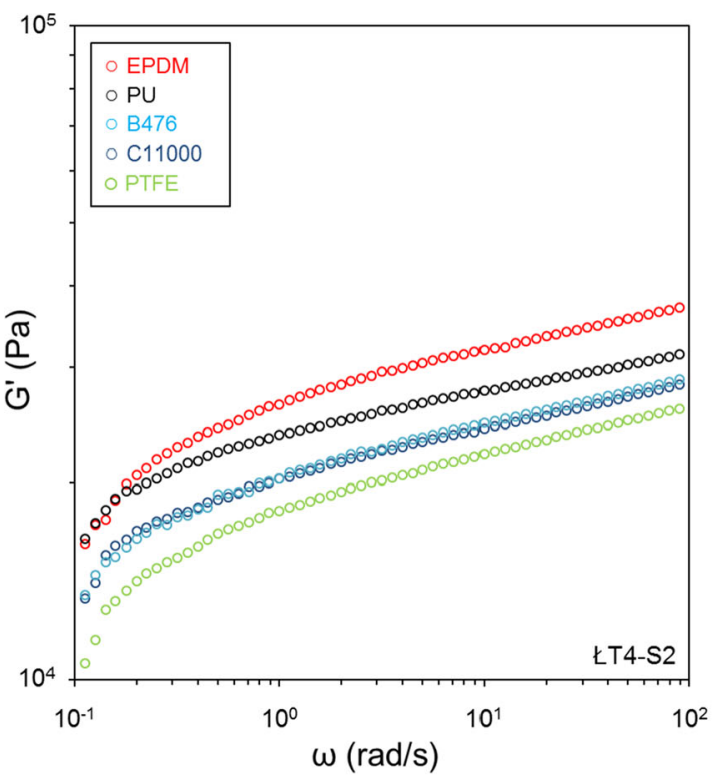

(a)

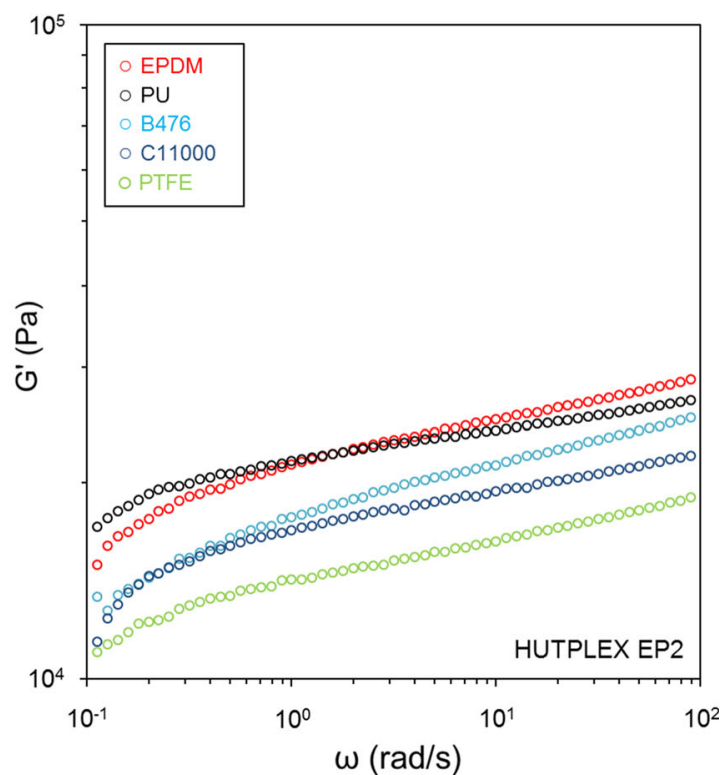

(b)

Fig. 6 Storage modulus $G^{\prime}$ of a lithium grease and $\mathbf{b}$ calcium grease versus oscillation frequency $\omega$, recorded in vicinity of tested adsorbents at temperature of $60{ }^{\circ} \mathrm{C}$

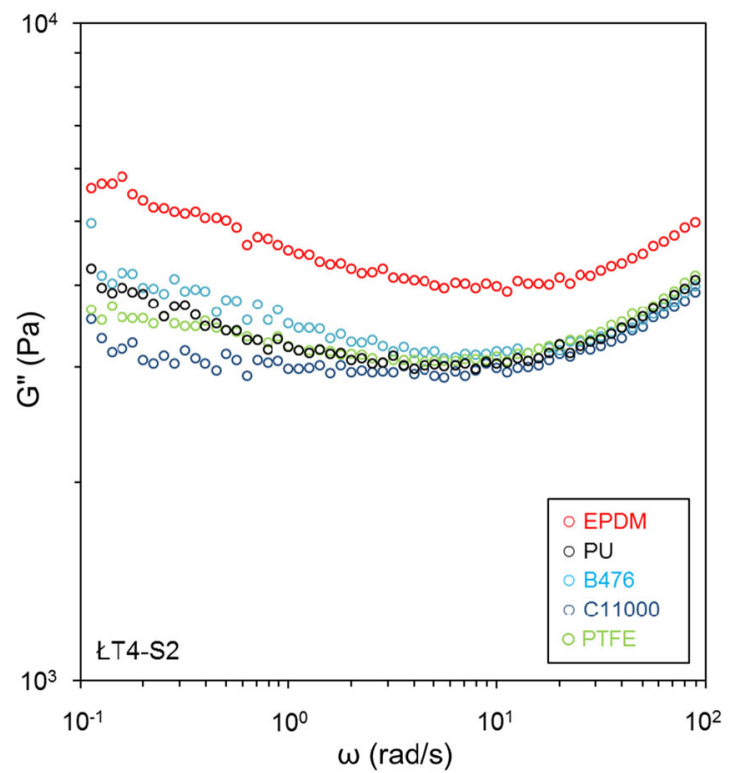

(a)

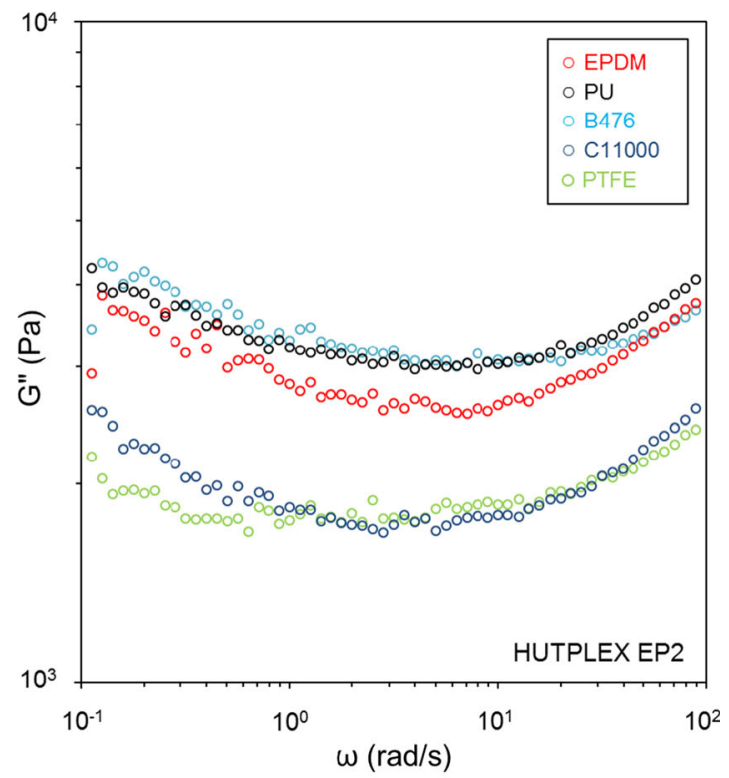

(b)

Fig. 7 Loss modulus $G^{\prime \prime}$ of a lithium grease and $\mathbf{b}$ calcium grease versus oscillation frequency $\omega$, recorded in vicinity of tested adsorbents at temperature of $60{ }^{\circ} \mathrm{C}$

to copper alloy $\mathrm{C} 11000$ and thermoplastic PTFE. In the case of $\mathrm{C} 11000$, they amounted to 24,371 and $19,623 \mathrm{~Pa}$ for, respectively, the lithium grease and the calcium grease. When flowing close to copper alloy $\mathrm{C} 11000$, the greases would form a distinct superficial layer.

\subsection{Energy State of Surface Layer of Adsorbents}

The energy state of the surface layer of the adsorbents was investigated using a goniometer. The adsorbent thermostating temperature during the measurements was kept at 


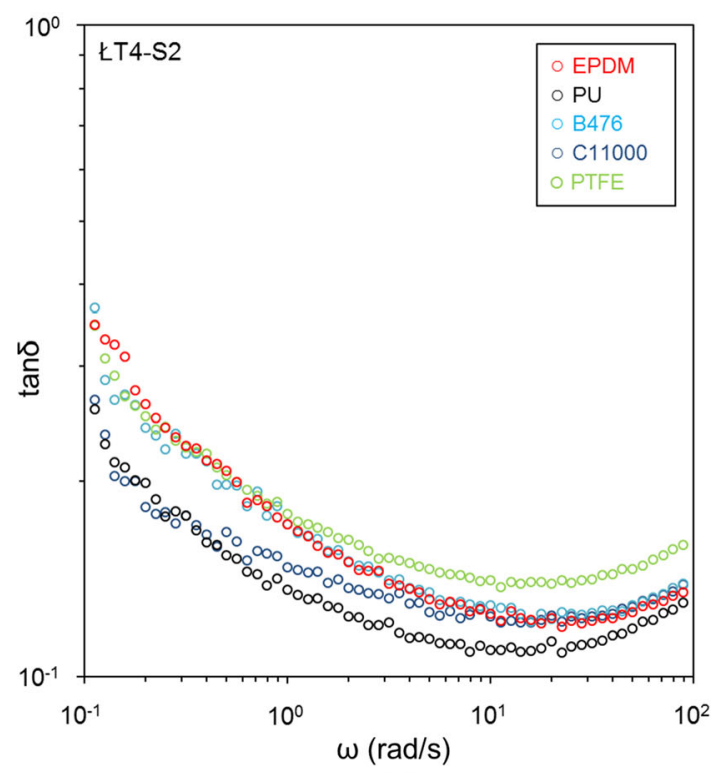

(a)

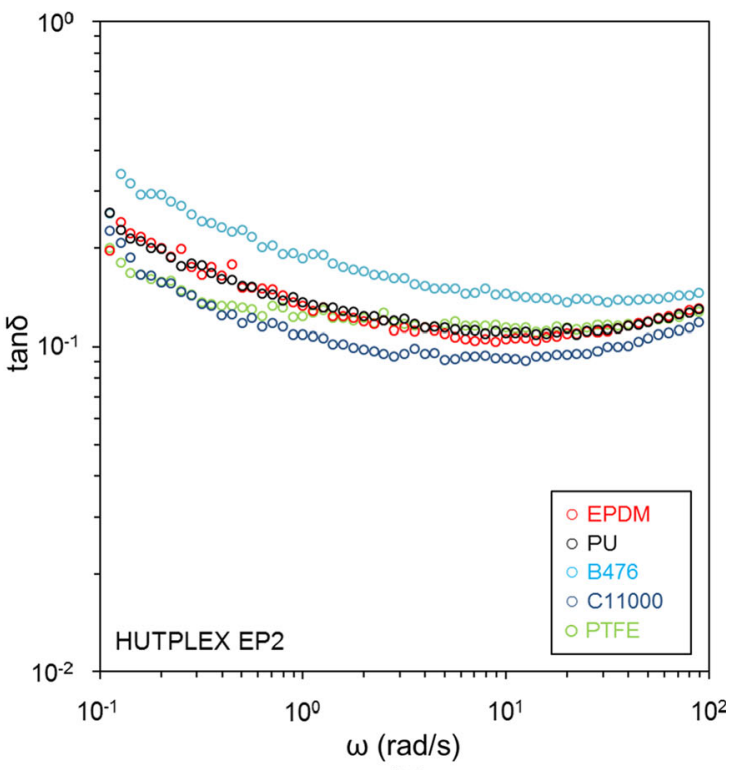

(b)

Fig. 8 Damping coefficient tan $\delta$ of a lithium grease and b calcium grease versus oscillation frequency $\omega$, recorded in vicinity of tested adsorbents at temperature of $60{ }^{\circ} \mathrm{C}$

Table 4 Results of measurements of plateau modulus $G_{N \exp }^{0}$ (in Pa) of greases, recorded in vicinity of tested adsorbents

\begin{tabular}{llrlrr}
\hline Material & \multicolumn{2}{l}{ Lithium grease } & & \multicolumn{2}{l}{ Calcium grease } \\
\cline { 2 - 3 } & Mean & SD & & Mean & SD \\
\hline EPDM & 34,294 & 2,447 & & 24,816 & 1,145 \\
B476 & 25,457 & 762 & & 22,429 & 657 \\
C11000 & 24,371 & 998 & & 19,623 & 763 \\
PTFE & 22,283 & 336 & & 16,636 & 275 \\
PU & 28,908 & 547 & & 23,711 & 597 \\
\hline
\end{tabular}

$60{ }^{\circ} \mathrm{C}$ since at this temperature, the influence (determined using the rotational rheometer) of the adsorbent wall material on the wall effects in the soap-based greases had been most visible. Table 5 shows the tested samples' surface layer contact angles $(\Theta)$ measured using the probe liquids. The results are presented as means with standard deviations.
Table 6 shows the results of the adsorbent surface layer energy state investigations, obtained on the basis of contact angle $\Theta$ measurements (Table 5) by means of the OwensWendt method and the $\mathrm{Wu}$ method. The investigations showed that the differences between the surface free energy (SFE) values determined by the two methods are slight. For the tested adsorbents, the highest surface free energy value was recorded for alloy C11000. The SFE value in this case amounted to 38.0 and $39.8 \mathrm{~mJ} / \mathrm{m}^{2}$ for the Owens-Wendt method and the Wu method, respectively. The values were slightly higher for the second of the tested alloys-bronze B476. In the case of the plastics, polyurethane PU was characterized by the highest surface free energy. The SFE values for this plastic amounted to, respectively, 32.6 and $33.8 \mathrm{~mJ} / \mathrm{m}^{2}$. From all the tested materials, polytetrafluoroethylene PTFE showed the lowest surface free energy. The SFE values in this case amounted to 25.7 and $29.1 \mathrm{~mJ} / \mathrm{m}^{2}$ and were higher than for $\mathrm{C} 11000$ by, respectively, 12.3 and $10.7 \mathrm{~mJ} / \mathrm{m}^{2}$.
Table 5 Measured contact angles $\Theta$ (in ${ }^{\circ}$ ) of adsorbents surface layer at temperature of $60{ }^{\circ} \mathrm{C}$

\begin{tabular}{|c|c|c|c|c|c|c|c|c|c|c|}
\hline \multirow[t]{2}{*}{ Material } & \multicolumn{2}{|c|}{ Pure water } & \multicolumn{2}{|c|}{ Diiodomethane } & \multicolumn{2}{|c|}{ Formamide } & \multicolumn{2}{|c|}{ Ethylene glycol } & \multicolumn{2}{|c|}{ Glycerol } \\
\hline & Mean & SD & Mean & SD & Mean & SD & Mean & $\mathrm{SD}$ & Mean & SD \\
\hline EPDM & 106.3 & 3.8 & 45.5 & 2.0 & 82.9 & 4.9 & 79.8 & 5.5 & 102.2 & 2.3 \\
\hline B476 & 84.7 & 7.1 & 45.9 & 1.4 & 65.6 & 3.9 & 71.8 & 4.8 & 86.2 & 4.9 \\
\hline C11000 & 87.3 & 3.8 & 50.0 & 2.1 & 65.7 & 6.7 & 63.9 & 3.9 & 86.6 & 3.8 \\
\hline PTFE & 94.6 & 4.2 & 78.1 & 2.8 & 82.0 & 4.3 & 77.6 & 5.0 & 77.3 & 4.8 \\
\hline PU & 87.8 & 2.7 & 67.0 & 2.3 & 70.3 & 5.0 & 64.2 & 3.7 & 95.3 & 5.2 \\
\hline
\end{tabular}


Table 6 Results of investigations of adsorbent surface layer energy state at temperature of $60{ }^{\circ} \mathrm{C}$ by Owens-Wendt and Wu methods

\begin{tabular}{|c|c|c|c|c|c|c|}
\hline \multirow[t]{2}{*}{ Material } & \multicolumn{3}{|c|}{ Owens-Wendt method } & \multicolumn{3}{|c|}{ Wu method } \\
\hline & $\begin{array}{l}\text { SFE } \gamma_{\mathrm{S}} \\
\left(\mathrm{mJ} / \mathrm{m}^{2}\right)\end{array}$ & $\begin{array}{l}\text { Dispersion component } \\
\gamma_{\mathrm{S}, \mathrm{d}}\left(\mathrm{mJ} / \mathrm{m}^{2}\right)\end{array}$ & $\begin{array}{l}\text { Polar component } \gamma_{\mathrm{S}, \mathrm{p}} \\
\left(\mathrm{mJ} / \mathrm{m}^{2}\right)\end{array}$ & $\begin{array}{l}\text { SFE } \gamma_{\mathrm{S}} \\
\left(\mathrm{mJ} / \mathrm{m}^{2}\right)\end{array}$ & $\begin{array}{l}\text { Dispersion component } \\
\gamma_{\mathrm{S}, \mathrm{d}}\left(\mathrm{mJ} / \mathrm{m}^{2}\right)\end{array}$ & $\begin{array}{l}\text { Polar component } \gamma_{\mathrm{S}, \mathrm{p}} \\
\left(\mathrm{mJ} / \mathrm{m}^{2}\right)\end{array}$ \\
\hline EPDM & 31.9 & 31.9 & 0 & 33.4 & 32.0 & 1.4 \\
\hline B476 & 35.9 & 33.0 & 2.9 & 39.4 & 32.6 & 6.8 \\
\hline C11000 & 38.0 & 36.1 & 1.9 & 39.8 & 33.7 & 6.1 \\
\hline PTFE & 25.7 & 21.8 & 3.9 & 29.1 & 21.3 & 7.7 \\
\hline PU & 32.6 & 30.9 & 1.8 & 33.8 & 28.2 & 5.6 \\
\hline
\end{tabular}

\section{Discussion}

The influence of the type of adsorbent and that of the temperature of -20 to $60{ }^{\circ} \mathrm{C}$ on changes in the structural viscosity in the boundary layer area of soap-based greases thickened with, respectively, lithium 12-hydroxystearate and overbased calcium sulfonate were assessed during the rheological tests conducted at a variable shear rate. The tests showed that the type of adsorbent had the greatest influence on the wall effects at the temperature of $60{ }^{\circ} \mathrm{C}$, whereas at $-20{ }^{\circ} \mathrm{C}$, it had the smallest influence. This was probably due to the increased mobility of the soap-based thickener particles in the two greases as the viscosity of the oil base decreased with increasing temperature. At $60{ }^{\circ} \mathrm{C}$, the superficial layer of the greases would quickly form on the metallic adsorbents, unlike in the case of the EPDM rubber and the PU thermoplastic. At above-zero temperatures, the lowest viscosity values were recorded for B476 and $\mathrm{C} 11000$ and the highest for EPDM and PU. At sub-

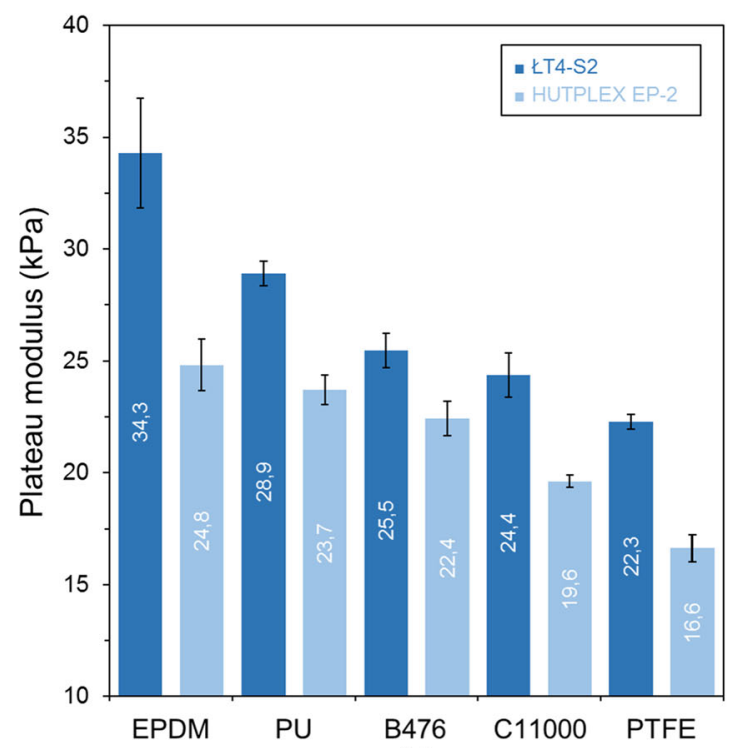

(a) zero temperatures, the opposite tendency was observed. The tests carried out at the temperature of $60{ }^{\circ} \mathrm{C}$, at which the intensity of changes in the boundary layer area of the greases was highest, indicate a strong correlation between the plateau modulus averages determined through dynamic oscillatory tests and the energy state of the surface layer of the adsorbents. Figure 9 shows that the plateau modulus value for the soap-based greases flowing in the vicinity of the adsorbents decreases as the free surface energy of the adsorbents, determined by means of the goniometer, increases. The only exception is thermoplastic PTFE whose surface layer is characterized by the lowest surface energy among all the tested materials. This indicates that there exists a certain minimum surface free energy of the adsorbents at which total slip of the grease occurs at the wall without any diffusion of soap-based thickener ensembles onto the surface being lubricated. In such cases, also a thickener-depleted layer, characterized by a low degree of microstructure cross-linking and initiating the

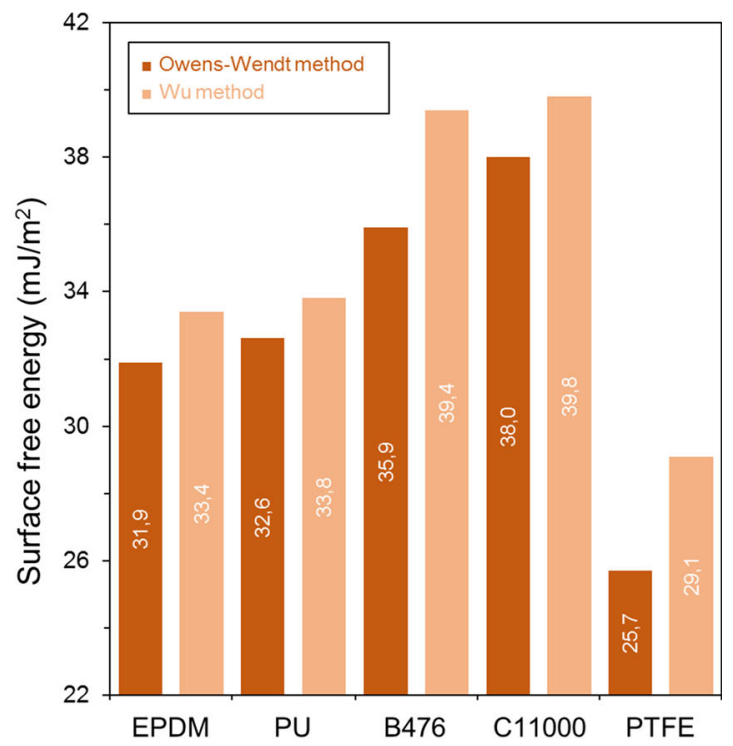

(b)

Fig. 9 Comparison of experimental plateau moduli $G_{N \exp }^{0}$ of greases and surface free energies $\gamma_{\mathrm{S}}$ of adsorbents at temperature of $60{ }^{\circ} \mathrm{C}$ 
slip of the grease, forms. Figure 9 also indicates that grease HUTPLEX EP-2 flowing in the vicinity of the tested adsorbents showed a much lower plateau modulus value than grease LT4-S2. Despite the fact that the oil base of grease HUTPLEX EP-2 was characterized by higher kinematic viscosity, its thickener particles, in the form of calcium sulfonate ensembles, would easier diffuse onto the wall surface, forming a superficial layer.

It should be emphasized that the test results obtained by the authors are true for the conditions prevailing during the experiment, i.e., the temperature ranging from -20 to $60{ }^{\circ} \mathrm{C}$, and for soap-based greases not subjected to prolonged intensive shearing. Thus, the test results can be applied to, for example, centralized machine lubrication systems to design lubrication conduits, distributors and valves, which will reduce flow resistances and curb the occurrence of dangerous inertial phenomena and lightly loaded sliding systems in which soap-based greases are not subjected to high shearing stresses. In the case of high-speed and/or heavily loaded lubricated rolling bearings, the fragmentation of the soap-based thickener microstructure and the high temperature can significantly affect the ability of the greases to form a superficial layer and a boundary layer.

\section{Conclusions}

Several significant conclusions emerge from the authors' rheological studies of the soap-based greases and the energy state of the adsorbents:

1. Commercial greases: LT4-S2 and HUTPLEX EP-2, thickened with, respectively, lithium 12-hydroxystearate and overbased calcium sulfonate, showed the ability to form thickener-depleted boundary layer in the vicinity of all the tested adsorbents.

2. The soap-based thickener used in the grease, the kind of adsorbent and temperature had an influence on the wall effects. In the case of grease LT4-S2 at the temperature of $-20^{\circ} \mathrm{C}$, no appreciable effect of the material on the formation of a boundary layer was observed.

3. The strongest influence of the tested adsorbents on the wall effects in the two soap-based greases was observed at the temperature of $60{ }^{\circ} \mathrm{C}$.

4. The rheological parameter: plateau modulus $G_{N}^{0}$, can be used as an indicator of a grease's ability to form a superficial layer. As a result of the intensive diffusion of thickener particles onto the adsorbent surface, the cross-linking of the microstructure in the boundary layer area and the plateau modulus decreases.

5. The surface free energy of the adsorbents, resulting from the electron structure of their surface layer, can induce such tribological and rheological phenomena as the formation of a lubricating film and the slip of grease in the vicinity of the wall.

Acknowledgements This research was funded by the Department of Fundamentals of Machine Design and Tribology at the Mechanical Engineering Faculty of Wroclaw University of Technology. The authors gratefully thank Stanisław Frackowiak, Ph.D., Eng. from the Advanced Polymer Materials and Recycling Laboratory at the Environmental Engineering Faculty of Wrocław University of Technology for his invaluable help in carrying out this research.

Open Access This article is distributed under the terms of the Creative Commons Attribution 4.0 International License (http://crea tivecommons.org/licenses/by/4.0/), which permits unrestricted use, distribution, and reproduction in any medium, provided you give appropriate credit to the original author(s) and the source, provide a link to the Creative Commons license, and indicate if changes were made.

\section{References}

1. Lugt, P.M.: Grease Lubrication in Rolling Bearings. John Wiley \& Sons, New York (2013)

2. Paszkowski, M.: Some aspects of grease flow in lubrication systems and friction nodes. In: Gegner, J. (ed.) TribologyFundamentals and Advancements, pp. 77-106. InTech, Rijeka (2013)

3. Sochi, T.: Slip fluid-solid interface. Polym. Rev. 51, 309-340 (2011)

4. Gow, G.: Lubricating grease. In: Mortier, R.M., Orszulik, S. (eds.) Chemistry and Technology of Lubricants, 2nd edn, pp. 306-319. Chapman \& Hall, London (1997)

5. Barnes, H.A.: A review of the slip (wall depletion) of polymer solution, emulsions and particle suspensions in viscometers: its cause, character and cure. J. Nonnewton. Fluid Mech. 56, 221-251 (1995)

6. Czarny, R.: The influence of the kind of the surface material on wall-effect of grease. In: Proceedings of 6th International Congress on Tribology, vol. 2, pp. 247-252. Budapest (1993)

7. Biernacki, K.: Influence of wall material type, shear rate and temperature on shear stress values in greases. Tribol. tarcie zużycie smarowanie 6, 75-85 (2007). (in Polish)

8. Czarny, R., Moes, H.: Some aspects of lubricating grease flow. In: Proceedings of 3rd International Conference on Tribology Eurotrib, vol. 3, pp. 68-85. Warsaw (1981)

9. Bramhall, A.D., Hutton, J.F.: Wall effect in the flow of lubricating greases in plunger viscometers. Br. J. Appl. Phys. 11, 363-396 (1960)

10. Paszkowski, M.: Effect of grease thickener and surface material on rheological properties of boundary layer. Colloids Surf. A $\mathbf{4 8 0}$, 462-467 (2015)

11. Delgado, M.A., Franco, J.M., Partal, P., Gallegos, C.: Experimental study of grease flow in pipeline: wall slip and air entrainment effects. Chem. Eng. Process. 44, 805-817 (2005)

12. Biernacki, K.: Investigations of shear stress during flow of greases in pipes. Hydraul. Pneumatyka 4, 13-15 (2004). (in Polish)

13. Duenas-Dobrowolski, J., Gawliński, M., Methods of visualizing grease movement in labyrinth seals (in Polish). In: Zeszyty energetyczne, Volume I, Contemporary Power Engineering Problems, pp. 79-86 (2014) 
14. Duenas-Dobrowolski, J., Gawliński, M., Determination of grease velocity profile in clearance of clearance seal by means of micro particle image velocimetry ( $\mu$ PIV) (in Polish). In: Zeszyty energetyczne, Volume II, Contemporary Power Engineering Problems, pp. 11-20 (2015)

15. Green, T.M., Baart, P., Westerberg, L.G., Lundstrom, T.S., Hoglund, E., Lugt, P.M., Li, J.X.: A new method to visualize grease flow in a double restriction seal using microparticle image velocimetry. Tribol. Trans. 54(6), 784-792 (2011)

16. Li, J.X., Westerberg, L.G., Hoglund, E., Lundstrom, T.S., Lugt, P.M., Baart, P.: Lubricating grease shear flow and boundary layers in a concentric cylinder configuration. In: 3rd International Tribology Symposium of IFToMM, pp. 45-56. Luleå (2013)

17. Poon, S.V.: An experimental study of grease in elastohydrodynamic lubrication. J. Lubr. Technol. 94(1), 27-34 (1972)

18. Czarny, R.: Studies of grease flow resistance in swinging bearings (in Polish). In: Scientific Papers of the Machine Design and Operation Institute at Wrocław University of Technology, 54, pp. 105-117 (1989)

19. Kaneta, M., Ogata, T., Takubo, Y., Naka, M.: Effects of a thickener structure on grease elastohydrodynamic lubrication films. Proc. Inst. Mech. Eng. Part J J. Eng. Tribol. 214(4), $327-336$ (2000)

20. Couronné, I., Vergne, P., Mazuyer, D., Truong-Dinh, N., Girodin, D.: Effects of grease composition and structure on film thickness in rolling contact. Tribol. Trans. 46(1), 31-36 (2003)

21. Cann, P.M.: Starved grease lubrication of rolling contacts. Tribol. Trans. 42(4), 867-873 (1999)

22. Lugt, P.M., Velickov, S., Tripp, J.H.: On the chaotic behaviour of grease lubrication in rolling bearings. Tribol. Trans. 52(5), 581-590 (2009)

23. Li, X.M., Guo, F., Wong, P.L.: Shear rate and pressure effects on boundary slippage in highly stressed contacts. Tribol. Int. 59, 147-153 (2013)

24. Wong, P., Li, X., Guo, F.: Evidence of lubricant slip on steel surface in EHL contact. Tribol. Int. 61, 116-119 (2013)

25. Kalin, M., Polajnar, M.: The effect of wetting and surface energy on the friction and slip in oil-lubricated contacts. Tribol. Lett. 52(2), 185-194 (2013)
26. Kalin, M., Velkavrh, I., Vižintin, J.: The Stribeck curve and lubrication design for non-fully wetted surfaces. Wear 267(5-8), 1232-1240 (2009)

27. Czarny, R.: The influence of surface material and topography on the wall effect of grease. Lubr. Sci. 14-2, 255-274 (2002)

28. Ferry, J.D.: Viscoelastic Properties of Polymers, 3rd edn. Willey, New York (1980)

29. Gennes, P.G.: Scaling Concepts in Polymer Physics. Cornell University Press, New York (1979)

30. Wu, S.: Chain structure and entanglement. J. Polym. Sci. Part B Polym. Phys. 27(4), 723-741 (1989)

31. Liu, C., He, J., Van Ruymbeke, E., Keunings, R., Bailly, C.: Evaluation of different methods for the determination of the plateau modulus and the entanglement molecular weight. Polymer 47(13), 4461-4479 (2006)

32. Żenkiewicz, M.: Adhesion and Modification of the Surface Layer of Macromolecular Plastics. Wydawnictwa Naukowo-Techniczne, Warsaw (2000). (in Polish)

33. Bellon-Fontaine, M.N., Mozes, N., van der Mei, H.C., Sjollema, J., Cerf, O., Rouxhet, P.G., Busscher, H.J.: A comparison of thermodynamic approaches to predict the adhesion of dairy microorganisms to solid substrata. Cell Biophys. 17(1), 93-106 (1990)

34. Busscher, H.J., van Pelt, A.W.J., de Boer, P., de Jong, H.P., Arends, J.: The effect of surface roughening of polymers on measured contact angles of liquids. Colloids Surf. 9, 319-331 (1984)

35. Chen, Jie-Rong, Wakida, T.: Studies on surface energy and surface structure of PTFE film treated with low temperature plasma. J. Appl. Polym. Sci. 63, 1733-1739 (1997)

36. Owens, D.K., Wend, R.C.: Estimation of the surface free energy of polymers. J. Appl. Polym. Sci. 13, 1741-1747 (1969)

37. Wu, S.: Polymer Interface and Adhesion. Marcel Deccer, New York (1982)

38. Young, T.: An essay on the cohesion of fluids. Philos. Trans. R. Soc. Lond. 95, 65-87 (1805) 